Int. J. Electrochem. Sci., 15 (2020) $137-148$

International Journal of

ELECTROCHEMICAL

SCIENCE

www.electrochemsci.org

\title{
Electrochemical Detection of Dopamine in Real Samples by an Indium Tin Oxide-Coated Glass Electrode Modified with Carbon Nanotubes
}

\author{
Bo Zhang ${ }^{1,2^{*}}$, Qiong $\mathrm{Wu}^{1,2^{*}}$, Ben $\mathrm{Li}^{3^{*}}$, Xin Tang ${ }^{4}$, Fei Ju ${ }^{2}$, QianQian Yang ${ }^{2}$, Qiuhong Wang ${ }^{2 \&}$, \\ You Lang Zhou ${ }^{2 \&}$ \\ ${ }^{1}$ The Medical School of Nantong University, Nantong 226001, P.R. China. \\ ${ }^{2}$ The Hand and Surgery Research Center, Department of Hand Surgery, Affiliated Hospital of Nantong \\ University, Nantong 226001, P.R. China \\ ${ }^{3}$ Department of Cardiothoracic Surgery, Affiliated Hospital of Nantong University, Nantong 226001, \\ P.R. China. \\ ${ }^{4}$ Key Laboratory of Neuroregeneration of Jiangsu and Ministry of Education, Co-Innovation Center of \\ Neuroregeneration, Nantong University, Nantong 226001, P.R. China. \\ ${ }^{*}$ These authors contributed equally to this study. \\ \&E-mail: 18260599796@163.com, zhouyoulang@ntu.edu.cn
}

doi: $10.20964 / 2020.01 .27$

Received: 11 September 2019 / Accepted: 21 October 2019 / Published: 30 November 2019

The development of inexpensive and simple analytical tools is of practical significance for biological sample analysis. This work developed a simple and cost-effective electrochemical sensor that was covered with filter paper and modified by multi-walled carbon nanotubes (MWCNTs) for selective and sensitive dopamine (DA) detection in animal tissue extracts. We extracted animal tissue samples with an acidified n-butanol $(1 \mathrm{ml} / \mathrm{g})$ homogenate in an ice bath suitable for electrochemical detection. A DA response is received at a very low potential $(0.43 \mathrm{~V}$ vs. $\mathrm{Ag} / \mathrm{AgCl})$ and is not affected by noradrenaline (NE) or 5-hydroxytryptamine (5-HT). We also investigated the correlation between analytical signals and the amount of assembled MWCNTs, as well as with the electrode area. The amperometric reaction to DA is found to be linear in a concentration range of $2.5 \times 10^{-8} \mathrm{M}$ to $1 \times 10^{-5} \mathrm{M}$, with a $5 \mathrm{nM}$ detection limit (signal-to-noise ratio of 3) under optimized experimental conditions. The method was further applied to quantify DA in the brain and tendon tissues of rats. The new method proposed is inexpensive, simple, and rapid compared to those of other conventional methods. It is pertinent to note that the sensor is a disposable, single-use sensor; thus, for every experiment, the electrode is prepared "as new". We presume that this approach is an effective mode for quantifying DA, which has great potential for future diagnostics of DA-related diseases.

Keywords: Dopamine; Electrochemical sensor; MWNTs; Diagnosis. 


\section{FULL TEXT}

(C) 2020 The Authors. Published by ESG (www.electrochemsci.org). This article is an open access article distributed under the terms and conditions of the Creative Commons Attribution license (http://creativecommons.org/licenses/by/4.0/). 